\title{
ESTIMATING THE BENEFIT FROM INDEPENDENT AGGREGATION IN THE DAY-AHEAD MARKET
}

\author{
K. Baltputnis*, Z. Broka \\ Riga Technical University, Institute of Power Engineering \\ 12-1 Azenes Str., Riga, LV-1048, LATVIA \\ *e-mail: karlis.baltputnis@rtu.Iv
}

As the EU countries are working on adapting the Electricity Directive to allow independent aggregation (IA) of demand response (DR) in all the electricity markets, this paper provides an assessment of potential benefits from DR in the day-ahead market, which has proven particularly challenging for the IA regulatory framework development. The model devised in this study uses data of the public wholesale market price curve from the Nord Pool power exchange to simulate market clearing results with introduction of certain amounts of DR that, via independent aggregation, competes alongside generation and is able to shift the supply curve. The simulated new market equilibrium point allows estimating price reduction capability of demand response, the total system-wide benefits, as well as analysing the potential remuneration mechanisms for independent aggregators and implications on their business models. While the results demonstrated a high value from DR during the peak hours, the overall benefits during average price periods were rather low, thus exposing the unpredictability of the revenue stream and questioning the business case for IA in the day-ahead market. The proposed approach can be used for further analysis of different IA compensation mechanisms, considering the system-wide benefits it brings to the wholesale market.

Keywords: Aggregation, compensation, day-ahead market price, demand response, electricity market. 
The Directive (EU) 2019/944 on common rules for the internal market for electricity calls for the European Union Member States to "allow final customers, including those offering demand response through aggregation, to participate alongside producers in a non-discriminatory manner in all electricity markets" [1]. Moreover, Articles 13 and 17 of the Directive specify that customers must be able to, without discrimination, establish contractual relations to aggregators who are not affiliated with their electricity suppliers. In essence, this requires setting up the role of an independent aggregator and mandates that such actors must be able to participate in all electricity markets, including balancing and wholesale markets.

While there have been a number of studies dealing with the key issues of independent aggregator participation in balancing markets [2], such as models for independent aggregator (IA) and supplier settlement [3]-[6], baseline calculation for estimating the amount of delivered demand response (DR) energy [7] and even impacts of the rebound effect [8], IA participation in wholesale markets (especially the dayahead market) alongside energy producers has generally been given less attention in the literature. Some notable exceptions are the studies performed by USEF [5], RAP [9] and SEDC [10]. Nevertheless, this topic is also of utmost importance in the light of implementing the Directive, and the EU Member States are looking for ways to make IA participation in electricity wholesale markets a reality [11]-[13].

Currently, France is a leader in Europe in IA access to markets, being one of the few countries where IAs can also participate in the wholesale market (through the NEBEF mechanism) [14]. However, as pointed out in [15], the assessment on whether the NEBEF mechanism sufficiently enables DR resources to fully participate in the market is mixed, and the rules still need to be adjusted. Moreover, $95 \%$ of the DR sector revenues in France are capacity-related (from ancillary service markets), showing that the energy potential might not be fully exploited in the wholesale market through NEBEF - "while the mechanism is innovative, it does not on its own sustain the aggregators' business models" [15]. One possible adjustment to the mechanism could be a premium paid to IAs reflecting the systemwide benefits brought, sourced from the electricity bills of all consumers. A similar DR-premium approach was already successfully challenged by consumer associations and competition authorities in 2015; however, as argued in [15], provisions set out in the Electricity Directive might reignite the debate.

Nevertheless, in most other parts of Europe, the mechanism for IA participation in wholesale markets has to be built from scratch, including in the Nordic/ Baltic region [11], where Nord Pool is the main nominated electricity market operator (NEMO). To establish such a mechanism, information on IA potential impact on the market is necessary. While there are a number of articles studying how DR in general can potentially influence the market price through increased price elasticity of the demand side, to the best of the authors' knowledge, this has not yet been assessed with the independent aggregator role in mind. The key difference here is that the aggregated demand response offered to the market by an integrated aggregator (i.e., retailer) could be expected to affect 
the demand curve of the market by modifying their demand bids to be more elastic, whereas an independent aggregator who is not its customers' retailer would conceivably participate in the supply side of the market (i.e., by selling 'non-consumption' alongside competing generation). This is a consequence to the way the bids are submitted to the market and afterwards aggregated in the supply and demand curves. The type of the order (buy or sell) is set by the sign of the number representing the bid volume, whereby a negative volume is a sell order and a positive volume is for buy. Consequently, the non-consumption (or consumption reduction) order would have a negatively signed volume and thus would be aggregated to the supply curve.

As a result, the retailer will have purchased some electricity its customers will not consume because of IA-induced DR. To alleviate this issue, a compensation can be envisioned whereby a trade is settled from the retailer to the IA for the DR energy at a certain price. However, if this price is set equal to the corresponding day-ahead price (which would ensure equal treatment of integrated and independent aggregators), this can completely negate any business case for IA participation in the day-ahead market [13]. The Directive, however, does allow for some flexibility in the setup of the compensation system, e.g., by taking into account the socio-economic benefits brought by IA activities [12]. In this study, one such approach has been considered.

The remainder of this paper is structured as follows. Section II outlines the methodology used for the estimation of potential day-ahead price reducing effect from IA participation in the Nord Pool market, making use of actual aggregated supply and demand bid data regularly published by the market operator. In Section III, the results of the assessment are presented, firstly, for a whole study year, and, secondly, for three particular hours discussed as case studies in more detail. Additionally, in this section, the results of a conceivable IA remuneration system are presented. Afterwards, the limitations of this study are summarised and their potential implications outlined. Finally, the conclusions are offered.

\section{METHODOLOGY}

\subsection{Overview}

In order to assess the potential impact of independent aggregation on the Nord Pool day-ahead market system price, system price curve data published by the market operator are used in this study. More specifically, the daily market clearing price (MCP) data reports [16] from 2018 have been utilised. These data files contain all price curve points and corresponding volumes, i.e., they do not contain information on individual bids, instead providing the data necessary to construct the demand and supply curves and identify their intersection. Thereby, it is possible to calculate the actual hourly system price, as well as simulate how the MCP would change if the demand or supply curves were modified, e.g., by introducing additional bids in the pool.

In this study, the supply curves for each day-ahead market trading time-step are modified by adding additional supply bids representing IA participation in the wholesale market as direct competitors to elec- 
tricity generators. The aggregate volume of the additional bids is set equal to a certain percentage of the original market clearing volume for each respective hour, whereas the corresponding bid price is set equal to $0.00 € / \mathrm{MWh}$ to ensure that the bids are accepted (there were no negative system prices recorded in 2018 [17] and a negative bid price for an IA would not be reasonable).

The overall algorithm of the study can be summarised as follows:

1. Download the MCP data report for day number 1.

2. Process the data from the downloaded file to enable its use in simulations. Each daily MCP data report file contains aggregated bid data for 24 hours (except for days with daylight saving time clock changes). Thereby the data need to be separated into hourly categories. Furthermore, the curve points initially only contain single hourly order information; thus, the accepted block order volumes for buy and sell blocks need to be added to the demand and supply curve points. Additionally, the volume for net flows has to be added to the demand curve if it is negative, and to the supply curve if it is positive [18].

3. To check the veracity of the obtained price curves, their intersection point is identified and compared to the known actual system price in the respective hour. Theoretically, these values should match completely or differ only marginally, which could be explained by

\subsection{Additional Analysis}

From the analysed dataset, three hours have been selected as case study examples for visualization of the price reducing effect, namely: 2018.03.01 8-9 CET (corresponding to the maximum system price of accumulated rounding errors in the price identification simulation process. More significant differences point to data trustworthiness issues and hours with such deviations ought to be disqualified from further analysis.

The method used to find the intersection of two curves defined by their points is the Fast and Robust Curve Intersection algorithm as described in [19].

4. If the original system price has been calculated with sufficient accuracy, the system price impacted by a certain amount of aggregated demand response is calculated - firstly, the IA bids are added to the supply curve; and, secondly, the new curve intersection point is found. This is the simulated system price with IA presence. Consequently, the price reduction effect is assessed.

5. The day number is incremented by one and steps 1 to 4 are repeated until day number 365 has been processed. The obtained results are then summarised and assessed.

The analysis of the hourly system prices outlined in these steps is carried out automatically with a dedicated MATLAB code developed for this purpose. Due to the significant volume of data, which need to be read and processed at each time step, the overall time of computation can be quite significant. The calculations for the year 2018 performed for this study took nearly 15 hours on a $2.40 \mathrm{GHz}$ computer with 16.0 GB operating memory utilising task parallelization on eight cores.
2018 - 198.27 €/MWh); 2018.06.19 20-21

CET (the average price $-43.99 € / \mathrm{MWh}$ ); 2018.10.15 0-1 CET (the minimum price $2.17 € / \mathrm{MWh})$.

Moreover, different amounts of the 
traded demand response are assessed and a conceivable aggregator compensation system is shown on the basis of these case studies, taking into account the overall reduction in electricity purchase costs, which is a societal benefit IAs can bring by participating in wholesale energy markets. The overall electricity purchase cost reduction is estimated by multiplying the actual and modelled decreased Nord Pool system price with the total energy volume traded at a particular hour in the day-ahead market.

In accordance with the demand response incentivization scheme proposed in [20], in these calculations, the IA does not receive direct remuneration for the nonconsumption sold as generation (implicitly, this remuneration is used to compensate the suppliers affected by the IA who have otherwise purchased energy they cannot sell to the intended customers). Instead, the IA is remunerated for the provided DR energy at a price derived from $1 / 3$ of the total systemwide savings resulting from the reduced market price.

\section{RESULTS AND DISCUSSION}

\subsection{Simulation Verification}

At this point, the first three steps of the overall algorithm described in Section 2.1 are performed. It is found that from the 8760 hours modelled, for 7740 of them (i.e., $88.36 \%$ ), the modelled Nord Pool system price is exactly equal to the actual recorded price. In Table 1, the differences in the remaining hours are summarised.

Table 1. Hours with Errors in the Modelled Year

\begin{tabular}{|c|c|c|c|c|c|c|}
\hline & \multicolumn{6}{|c|}{ Error (€/MWh) } \\
\hline & $>0.00$ & $>0.01$ & $>0.02$ & $>0.05$ & $>0.10$ & $>0.50$ \\
\hline Numb. of hours & 1020 & 439 & 126 & 47 & 38 & 14 \\
\hline$\%$ of hours & $11.64 \%$ & $5.01 \%$ & $1.44 \%$ & $0.54 \%$ & $0.43 \%$ & $0.16 \%$ \\
\hline Average error (€/MWh) & 0.02 & 0.06 & 0.20 & 0.54 & 0.66 & 1.75 \\
\hline
\end{tabular}

Evidently, the MCP identification model is overall well suited for calculating the Nord Pool day-ahead market system price using the aggregated demand and supply curves published by the market operator. For $11.64 \%$ of hours, there are deviations from the actual market price, but only for $0.16 \%$ of all the hours these deviations exceed $0.50 € / \mathrm{MWh}$. The average error is equal to $0.02 € / \mathrm{MWh}$. Curiously, the largest differences in the modelled prices are observed for 2 January 2018 (maximum error $-3.65 € / \mathrm{MWh}$ and only the first six hours of the day were modelled correctly).
The calculation mismatches from this day heavily skew the overall error statistics.

Overall, while the minor differences up to the average error of $0.02 € / \mathrm{MWh}$ could be explained by accumulated rounding issues in the price identification algorithm or the post-processing of the results, larger mistakes in the remaining 126 hours are harder to explain and possibly point to input data quality issues. Unfortunately, the authors do not have information which would allow rectifying these issues, thereby all the hours where the simulation error exceeds $0.02 € /$ MWh are excluded from the further analy- 
sis to maintain integrity of the results. These discarded data-points comprise generally average-level price hours (in the range of about $24-67 € / \mathrm{MWh}$ ) and thus their exclusion is not expected to significantly affect the results.

\subsection{Demand Response Induced Price Reduction Simulation}

In the remaining 8634 hours that have been verified as having sufficiently trustworthy original price curve data, the fourth step of the overall algorithm is carried out by introducing an additional supply bid to the price curve from IA equal to $1 \%$ of the original market clearing volume at each hour and recalculating the resulting reduced Nord Pool system price. It is assumed that the IA bid price is $0.00 €$. Consequently, the potential price reduction at each modelled hour can be quantified.
Overall, within the assessed hours, the average price reduction is equal to $0.98 € /$ MWh with the median being $0.38 € / \mathrm{MWh}$, whereby the minimum identified reduction is $0.07 € / \mathrm{MWh}$ and maximum $-78.35 € /$ MWh. As can be discerned from Fig. 1, the price reducing effect is generally quite modest, i.e., in $63.02 \%$ of the hours, it is less than $0.50 € / \mathrm{MWh}$, and only in $0.47 \%$ of the hours it is equal to or exceeds $4.50 € /$ $\mathrm{MWh}$.

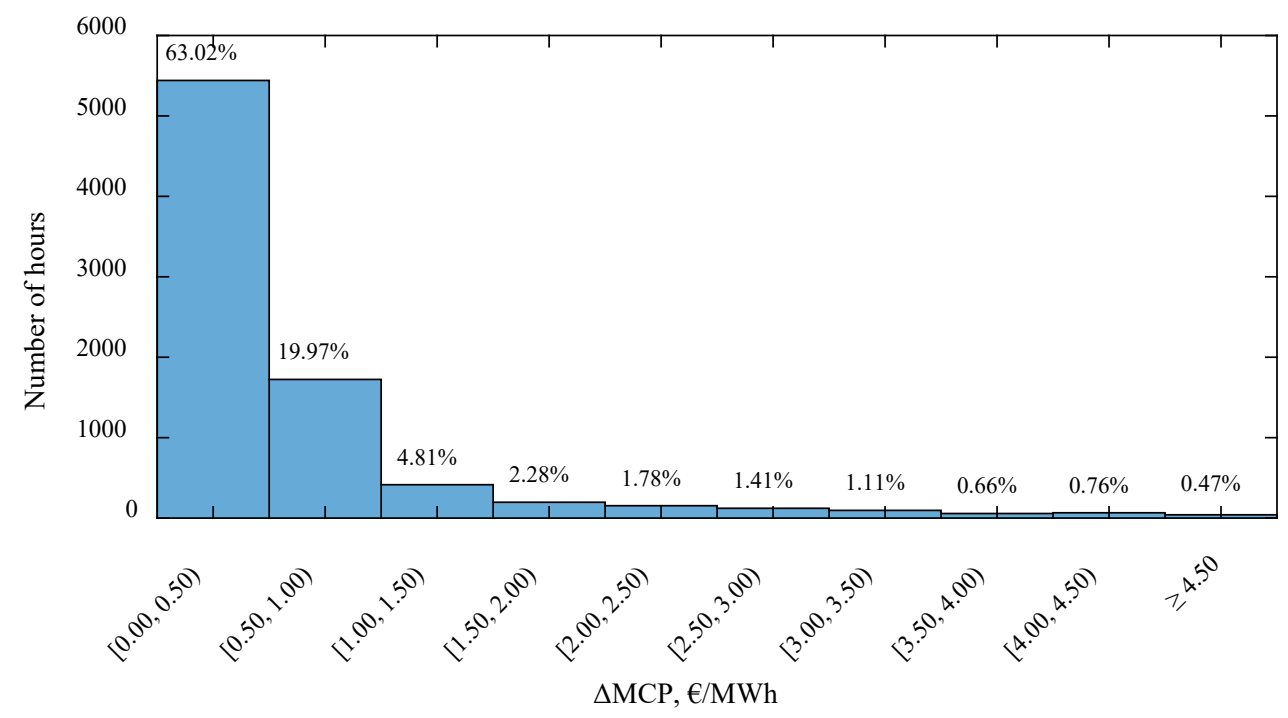

Fig. 1. Histogram of the price reduction effect achieved with $1 \%$ DR.

Figure 2 illustrates the correlation of the price reduction effect to the original Nord Pool system price. As can be seen on the $\mathrm{x}$-axis of the figure, very high system prices are quite exceptional. There are four points which are noticeably distant from the rest of the data, with the yearly price maxi- mum being a clear outlier (at the top-right corner of the chart).

Evidently, the simulated price reduction is higher when the original price itself is high. However, there is another cluster of reductions significantly above the average when the original price is about $20 € / \mathrm{MWh}$. 


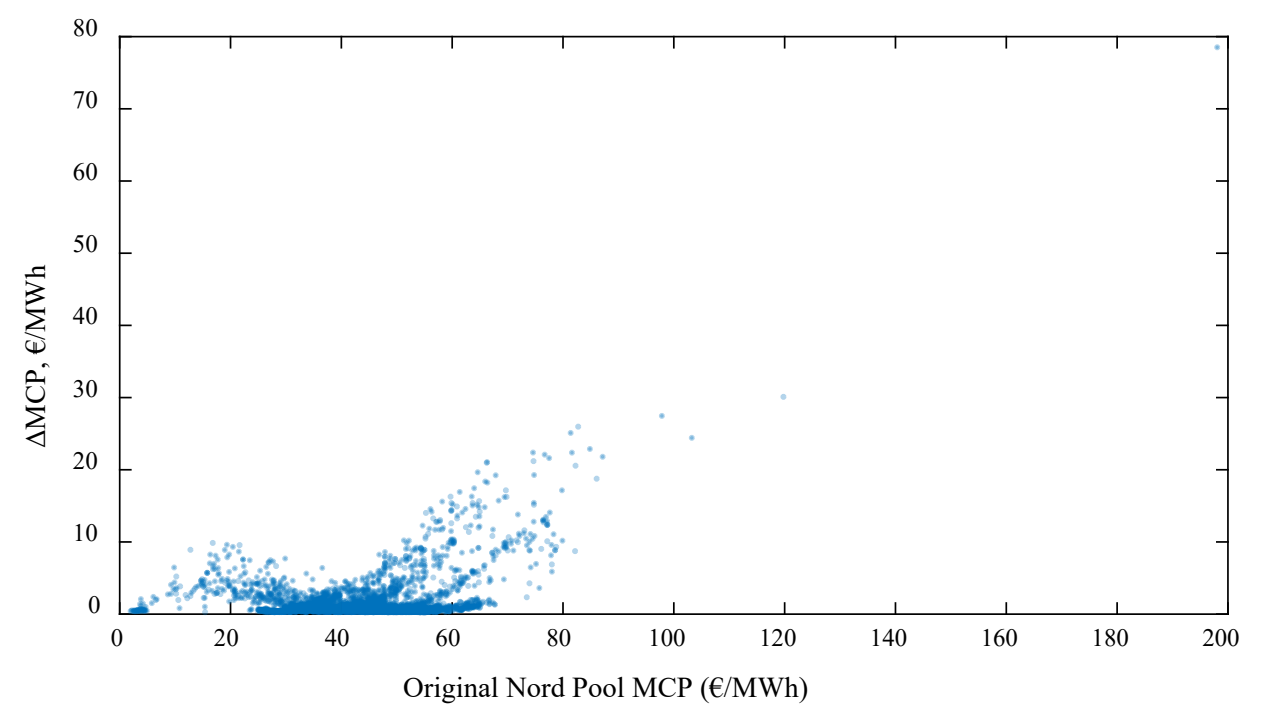

Fig. 2. Price reduction vs original system price (1\% DR).

\subsection{Particular Examples}

In this subsection, three particular hours from the simulated year 2018 are presented in more detail, also explaining visually the demand response induced wholesale price reduction if IA offers compete with generators on the supply side of the market. In Figs. 3-5, the blue line indicates the demand curve, the orange line indicates the original supply curve, and the yellow line indicates the appended supply curve, which includes the IA offers of aggregated demand response. As expected, as a consequence of the additional offers, the supply curve gets shifted to the right. In the figures, the left charts show the full demand and supply curves, whereas the right charts are zoomed in on the intersection points, which identify the original and the reduced MCP. In these figures, the energy volume of IA offers is set equal to $1 \%$ of the original market clearing volume.

On the other hand, in Tables 2-4, this volume varies from $0.01 \%$ to $5 \%$. Additionally, in these tables, the price reduction in each case is quantified together with the corresponding hypothetical decrease in the total electricity purchase cost in the Nord Pool.

For the maximum system price case (2018.03.01 8-9 CET), the results are shown in Fig. 3 and Table 2. Evidently, quite significant price reductions can be achieved in this case even with relatively modest amounts of DR energy (e.g., $14.72 € / M W h$ price reduction with $0.1 \%$ / $62.97 \mathrm{MWh}$ of DR). With a large DR volume (e.g., $5 \%$ / $3.2 \mathrm{GWh}$ ), the price can even be reduced to a nearly average level $-49.14 € / M W h$ in this example.

Table 2. System Price and Total Cost Reduction with Various DR Amounts (at max. price)

\begin{tabular}{|l|c|c|c|c|c|c|}
\hline DR, \% of volume & $\mathbf{0 . 0 1} \%$ & $\mathbf{0 . 0 5} \%$ & $\mathbf{0 . 1 0} \%$ & $\mathbf{0 . 5 0} \%$ & $\mathbf{1 . 0 0} \%$ & $\mathbf{5 . 0 0} \%$ \\
\hline $\mathrm{DR}, \mathrm{MWh}$ & 6.30 & 31.48 & 62.97 & 314.84 & 629.68 & 3148.40 \\
\hline $\mathrm{MCP}_{\text {new }}, \mathrm{MWh}$ & 198.22 & 183.55 & 180.07 & 177.22 & 119.92 & 49.14 \\
\hline$\Delta \mathrm{MCP}, € / \mathrm{MWh}$ & 0.05 & 14.72 & 18.20 & 21.05 & 78.35 & 149.13 \\
\hline Total cost reduction, $€$ & 2879 & 926607 & 1145861 & 1325619 & 4933706 & 9390477 \\
\hline
\end{tabular}



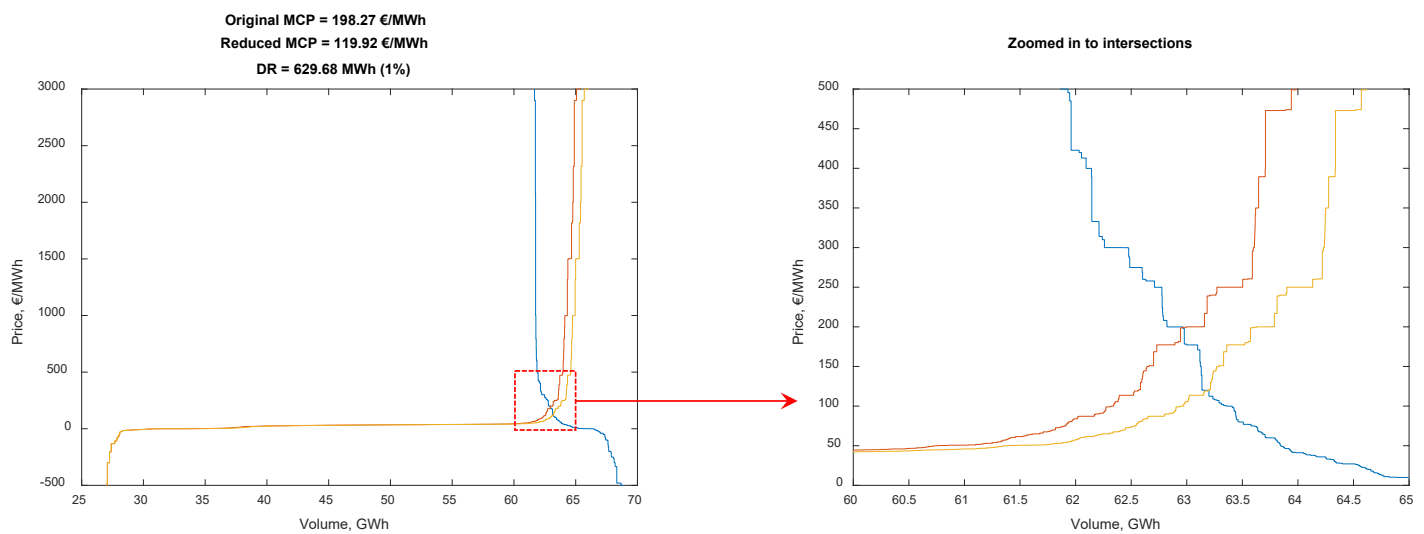

Fig. 3. Modelled market equilibrium at the maximum system price and $1 \% \mathrm{DR}$.

For the average system price case (2018.06.19 20-21 CET), the results are shown in Fig. 4 and Table 3. Here the price reductions are significantly lower, even miniscule (e.g., with a fairly large volume of DR equal to $1 \%$ of the total traded energy, the resulting system price decreases by only $0.15 € / M W h)$. However, this is well in line with the previously shown results for the whole year. As already concluded from Fig. 1, in the vast majority of hours in the year, the price reduction with $1 \% \mathrm{DR}$ is in the range of only $0.00-0.50 € / \mathrm{MWh}$. Moreover, with relatively low DR volumes $(0.01-0.1 \%)$, price reductions are barely attainable at all.

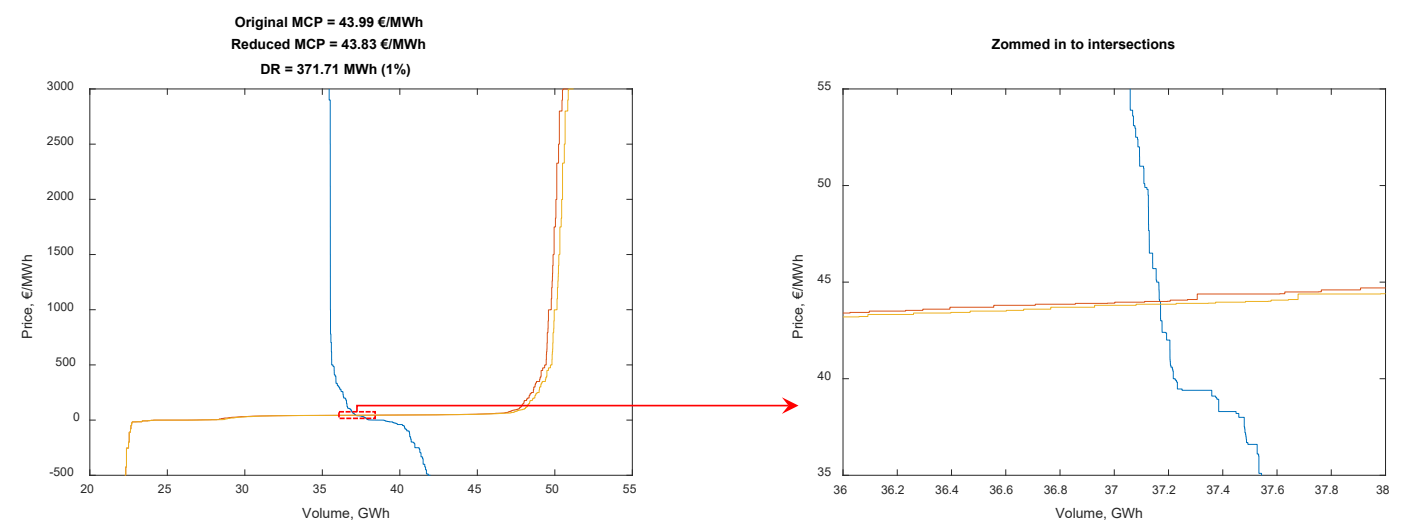

Fig. 4. Modelled market equilibrium at the average system price and $1 \%$ DR.

Table 3. System Price and Total Reduction with Various DR Amounts (at average price)

\begin{tabular}{|l|c|c|c|c|c|c|}
\hline DR, \% of volume & $\mathbf{0 . 0 1} \%$ & $\mathbf{0 . 0 5} \%$ & $\mathbf{0 . 1 0} \%$ & $\mathbf{0 . 5 0} \%$ & $\mathbf{1 . 0 0} \%$ & $\mathbf{5 . 0 0} \%$ \\
\hline $\mathrm{DR}, \mathrm{MWh}$ & 3.72 & 18.59 & 37.18 & 185.85 & 371.70 & 1858.53 \\
\hline $\mathrm{MCP}_{\text {new }}, \mathrm{G} / \mathrm{MWh}$ & 43.99 & 43.98 & 43.97 & 43.90 & 43.83 & 42.97 \\
\hline$\Delta \mathrm{MCP}, € / \mathrm{MWh}$ & 0.00 & 0.01 & 0.02 & 0.08 & 0.15 & 1.02 \\
\hline Total cost reduction, $€$ & 0 & 316 & 632 & 3125 & 5743 & 37807 \\
\hline
\end{tabular}


For the minimum system price case (2018.10.15 0-1 CET), the results are shown in Fig. 5 and Table 4. Counterintuitively, in this case, the price reducing effect is more pronounced than in the average system price case. This can to some extent be explained by the fact that, in this case, the original market equilibrium point happened to be in the vicinity of several major steps in both the demand and supply curve. This can be well seen in the zoomed sec- tion of Fig. 5. Nevertheless, a general effect of DR having more notable price reduction capacity when the original system price is low could not be observed and, mostly, the opposite is true as shown in Fig. 2.

Another important point regarding this case study is that, in general, it is quite unrealistic in terms of aggregator willingness to bid at such a low price. However, it does serve well in showing the theoretical effect for comparison purposes.
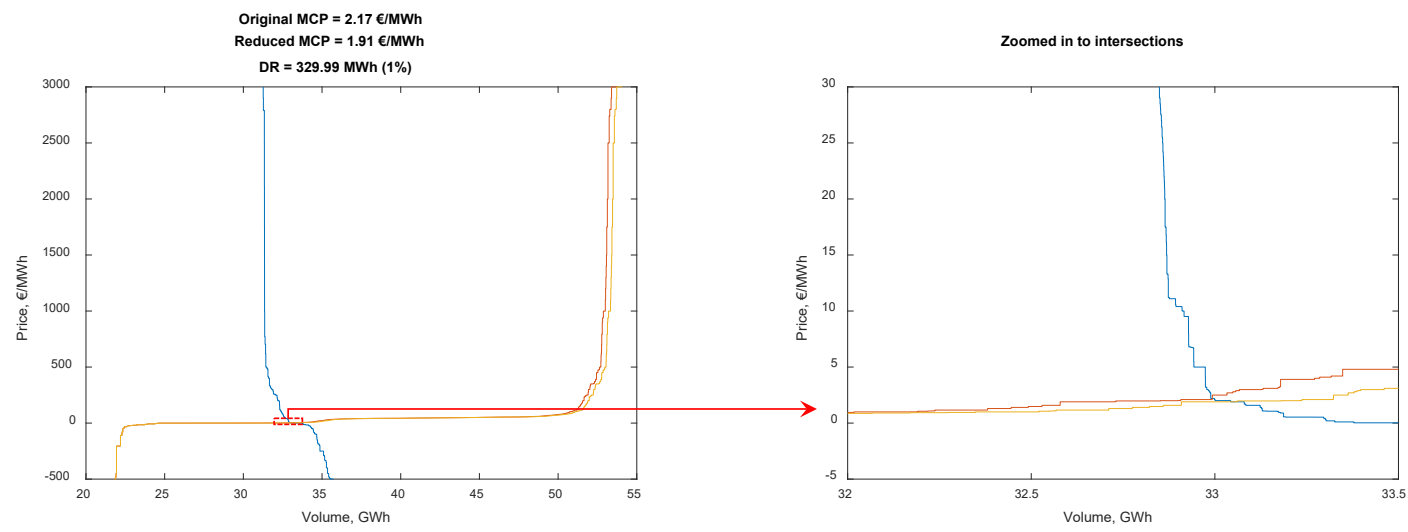

Fig. 5. Modelled market equilibrium at the minimum system price and $1 \%$ DR.

Table 4. System Price and Total Cost Reduction with Various DR Amounts (at min. price)

\begin{tabular}{|l|c|c|c|c|c|c|}
\hline DR, \% of volume & $\mathbf{0 . 0 1} \%$ & $\mathbf{0 . 0 5} \%$ & $\mathbf{0 . 1 0} \%$ & $\mathbf{0 . 5 0} \%$ & $\mathbf{1 . 0 0} \%$ & $\mathbf{5 . 0 0} \%$ \\
\hline $\mathrm{DR}, \mathrm{MWh}$ & 3.30 & 16.50 & 32.00 & 164.00 & 329.99 & 1649.96 \\
\hline $\mathrm{MCP}_{\text {new }}, € / \mathrm{MWh}$ & 2.15 & 2.10 & 2.08 & 1.99 & 1.91 & 0.81 \\
\hline$\Delta \mathrm{MCP}, € / \mathrm{MWh}$ & 0.02 & 0.07 & 0.09 & 0.18 & 0.26 & 1.36 \\
\hline Total cost reduction, $€$ & 882 & 2587 & 2996 & 6080 & 8652 & 45125 \\
\hline
\end{tabular}

It follows from both the whole year analysis and more detailed particular hour case studies that DR direct participation (on the supply side, via independent aggregators) in the Nord Pool market does not significantly affect the system price if it initially (i.e., without IAs) is small or even at about the average price levels. This verifies the conclusion from [21], whereby, using different methodology (multivariate adaptive regression spline), and focusing specifically on the Latvian bidding area of Nord Pool, it was found that for hours with average consumption, costs of energy production changed little with $1 \mathrm{MWh}$ shift in consumption, because the production cost curve was relatively flat in this region.

However, when the initial prices are high, the potential price reducing effect becomes more pronounced. Still, it takes very high amounts of DR to drive the price from maximum to close to average. 
The reasons can be well understood by studying a typical electricity wholesale market supply curve (Fig. 6). If the demand curve crosses the supply curve in the region marked by the green dashed line, then, quite obviously, even fairly small shifting of the curves (along the x-axis) can cause notable change in the market equilibrium i.e., the market clearing price. On the other hand, if the curve intersection is within the comparatively flat region marked by the blue dashed line, shift along the $\mathrm{x}$-axis can only cause a considerably smaller price change effect.

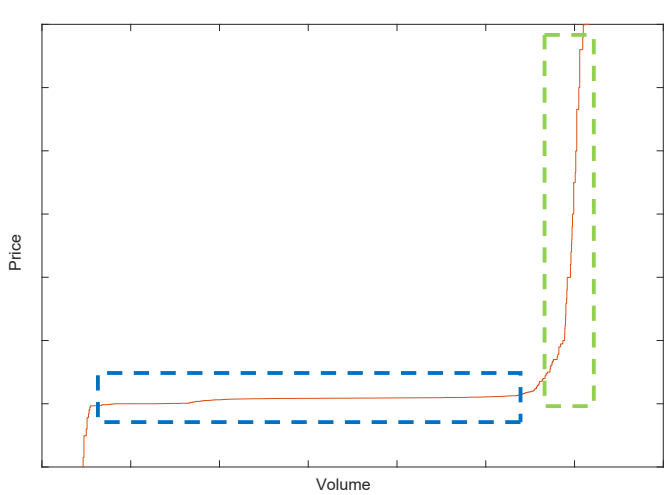

Fig. 6. Typical electricity wholesale market supply curve.

\subsection{IA Compensation Based on Socio-Economic Benefit}

It follows from the results presented in the previous subsections that the participation of aggregated DR in the electricity wholesale market has some capacity to reduce the market price and consequently the total electricity purchase cost. This would bring direct benefit to all the retailers who procure energy on the wholesale level, as well as to those consumers who have dynamic electricity tariffs (i.e., tied to the hourly day-ahead price). The retailers can be expected, in time, to pass some of this accrued benefit down to also those clients who have fixed price tariffs, thereby disseminating to consumers the overall socioeconomic benefit created by IAs in the form of reduced electricity prices.

However, those retailers who have customers in their portfolio engaged with independent aggregators could be placed in unfair position compared to competitors whose clients are not affiliated with any IAs (because of the purchased/forecasted but unserviceable energy). If this issue is alleviated similarly as how has been proposed for IA participation in balancing markets (via compensation set at the day-ahead price)
[11], the net position of IAs is equal to zero. Thereby, to not discourage IA participation in the day-ahead market, alternative solutions need to be identified.

Table 5 quantifies the benefit per unit of energy the IAs could be entitled to if a similar remuneration scheme as in [20] were to be applied - by sharing part (1/3) of the total cost savings with the IAs presumably responsible for the overall cost reduction (i.e., taking into account the system price reduction and the total energy traded in the Nord Pool day-ahead market at the respective hour). It is implied that the IAs would have to share this remuneration also with the customers they are aggregating to incentivize their engagement in direct demand response.

The potential remuneration in the average price case is quite small (5-7 €/MWh) and likely insufficient for a viable business case of independent aggregator participation in the Nord Pool day-ahead market. Even though, in the minimum price case, the theoretical compensation is noticeably larger, as discussed previously, DR during low price periods is unlikely. However, in 
the maximum price case, the remuneration per unit of energy is quite significant, albeit it tends to decrease if the volume of DR energy in the market grows considerably.

Table 5. Potential Remuneration to IAs Participating in the Day-Ahead Market

\begin{tabular}{|l|c|c|c|c|c|c|}
\hline DR, \% of volume & $\mathbf{0 . 0 1} \%$ & $\mathbf{0 . 0 5} \%$ & $\mathbf{0 . 1 0} \%$ & $\mathbf{0 . 5 0} \%$ & $\mathbf{1 . 0 0} \%$ & $\mathbf{5 . 0 0} \%$ \\
\hline $\begin{array}{l}\text { Remuneration to } \\
\text { DR providers, } \boldsymbol{€} / \mathbf{M W h}:\end{array}$ & & & & & & \\
\hline The maximum price case & 152.33 & 9811.60 & 6065.65 & 1403.48 & 2611.75 & 994.21 \\
\hline The average price case & 0.00 & 5.67 & 5.67 & 5.60 & 5.15 & 6.78 \\
\hline The minimum price case & 89.09 & 52.26 & 31.21 & 12.36 & 8.74 & 9.12 \\
\hline
\end{tabular}

Overall, the results presented point to the potential value of independent aggregator participation in the day-ahead market specifically as actors aiming to benefit from their ability to reduce exceptionally high market prices. While there are relatively few hours annually when the system price is significantly above average levels

\subsection{Study Limitations and Discussion}

The results presented in this paper have to be interpreted in conjunction with the limitations inherent in the design and input data of the study. Most importantly, the market clearing simulations and the consequent assessment of potential for price reductions is based solely on the Nord Pool system price. In reality, because of congestions in the interconnections between various bidding zones, the actual market clearing price in the various bidding zones differs from the system price. Unfortunately, the publicly available bidding data published by Nord Pool are aggregated for the whole market and do not distinguish bids based on the bidding zone where they have been placed. Thereby, there is insufficient information to employ these historical bid-based data to perform price identification in specific bidding zones. It could be hypothesised that IA direct participation in the wholesale market might be most valuable in times when due to interconnector congestions there are exceptional price peaks in bidding zones
(Fig. 2), the very high specific (per unit of DR energy) benefit obtainable in such cases could point to a potentially feasible business model. However, further studies would be necessary to evaluate it, also taking into account the costs associated with independent aggregator operations.

with structural generation shortages.

Another limitation of the price recalculation approach used in this study is that it does not consider the potential impact of demand response on the market flows to and from bidding areas neighbouring the Nord Pool zones. In other words, the net flows to other areas are assumed independent from DR volume. Similarly, potential impacts of block bid peculiarities (e.g., paradoxical rejections) are not considered, since the data available do not allow for that, and neither are any potential impacts on the bidding behaviour of other market participants taken into account, although that can be expected to not be overly pronounced. Moreover, price recalculations were based solely on historical data, disregarding potential future evolution in the production and consumption structure in the region.

Furthermore, the total benefit (in the form of cost reduction) based approach to IA remuneration assessed in Section 3.4 has 
certain challenges which would need to be overcome for this model to be practically applicable in the Nord Pool areas. Firstly, the entity administering IA settlement and remuneration would need to have the technical capability to calculate (or a regulatory capability to request from market operators) the MCP (i.e., rerun the market clearing algorithm) in a counterfactual case without IA participation, to accurately assess their contribution to price reduction and consequent remuneration. As pointed out by [22], such recalculation can be extremely costly: "it requires definition of the methodology, data collection and analysis, sending the information to stakeholders, sending and paying invoices, all of which will be paid for by consumers". Moreover, DR deployed in one country would inevitably also bring some market price reductions in other countries because of market coupling. Thereby, such a remuneration mechanism would need coordinated and harmonised actions of the responsible authorities of many countries. The solution to this issue could prove even more challenging in a multiNEMO environment. These issues are not as relevant in situations where the market is run by a centralised entity also responsible for the settlements and without significant market coupling to neighbouring countries, such as the case in Singapore from where the proposed remuneration scheme is sourced [20]. Furthermore, introduction of premiums to DR aggregators formerly proposed in France for residential DR has been heavily criticised as offering unjustifiable subsidies, inviting market manipulation, and aggregator's direct participation in the wholesale market being altogether an inherently flawed business model [22], [23].

Nevertheless, national regulations regarding IA participation in wholesale markets is only part of the overall IA regulatory framework, which needs to be developed in each EU Member State in line with the Clean Energy Package [24], [25]. On the other hand, Article 59 of the Regulation on the internal market for electricity [26] empowers the European Commission to establish network codes in a number of areas, including the rules on aggregation. Such an approach would aid in the creation of harmonised IA frameworks across the EU.

\section{CONCLUSIONS}

The devised method demonstrated a very good accuracy in simulating the system-wide market clearing price and volume based on the public day-ahead market data available from the Nord Pool power exchange. While in this study the approach was employed for evaluating the potential impact of load-reducing demand response participation in the market, it could also be used for studying other wholesale market operation aspects in the Nordic-Baltic region based on the system curve data.

The impact of DR was simulated for the year 2018, which included both very high and very low prices occasionally. It was assumed that independent aggregation of DR participated in the market alongside generation, offering load-reducing demand response with a volume equal to $0.01-5 \%$ relative to the original market clearing volume. Case studies with $1 \%$ of DR were analysed in more detail. Over the whole year, DR addition of $1 \%$ in most cases $(63 \%)$ reduced the price by less than $0.50 € / \mathrm{MWh}$. The price decrease was larger than $1 € /$ MWh only in $17 \%$ of the simulated hours. 
However, quite significant price reduction was achieved for the maximum system price case, even with modest amounts of DR energy provided: namely, the price reduced by $78.35 € / \mathrm{MWh}$ with $1 \% \mathrm{DR}$, and overall the price decrease varied between $14.72 \ldots 149.13 € / \mathrm{MWh}$ with $0.05 \ldots .5 \%$ of DR. These results imply that DR might be particularly useful with extremely high market prices or during generation scarcity when the system-wide benefits from DR participation are the highest.

When studying the potential compensation to the independent DR aggregator based on a model whereby $1 / 3$ of the total system-wide savings is distributed among DR providers, the remuneration per unit of DR energy varied a lot among the different case studies. For the maximum price case, the largest remuneration (9811.60 €/MWh) was achieved with $0.05 \%$ of DR. However, it tended to decrease with larger penetration of DR implying self-cannibalization. For the average system price case, the compensation for DR energy was always less than
$7 € / \mathrm{MWh}$, likely indicating overall insufficient revenue for a viable business case. In contrast, with the lowest system price, the payments for DR were much larger varying between $9 . . .89 € / \mathrm{MWh}$.

As the EU Member States need to accommodate independent aggregation in all their electricity markets, one of the key issues is a reasonable, fair and nondiscriminatory compensation mechanism between independent aggregators and other market participants. To that end, the approach presented in this paper could be useful for assessing the impact of different policies and regulation on the IA business models, considering also the societal benefits brought about by independent aggregation and demand response as suggested by the EU Electricity Directive. One promising direction for the future work is consideration of the social welfare increase as opposed to electricity cost reduction as the main benefit and assessing how various compensation levels could affect that.

\section{ACKNOWLEDGEMENTS}

The authors would like to thank Tim Schittekatte (FSR) for the valuable discussion on this study. The authors also wish to express their gratitude to the anonymous reviewer for their remarks and suggestions on improving the manuscript.
The research has been funded by the Ministry of Economics of the Republic of Latvia, project "Innovative Smart Grid Technologies and their Optimization (INGRIDO)", project No. VPP-EMINFRA-2018/1-0006.

\section{REFERENCES}

1. EU. (2019). Directive (EU) 2019/944 of the European Parliament and of the Council of 5 June 2019 on common rules for the internal market for electricity and amending Directive 2012/27/EU. Official Journal of the European Union.
2. Poplavskaya, K., \& de Vries, L. (2018). A (not so) independent aggregator in the balancing market theory, policy and reality check. In 2018 15th International Conference on the European Energy Market (EEM), (pp. 1-6), 27-29 June 2018, Lodz, Poland. 
3. Sadovica, L., Marcina, K., Lavrinovics, V., \& Junghans, G. (2017). Facilitating energy system flexibility by demand response in the Baltics - Choice of the market model. In 2017 IEEE 58th International Scientific Conference on Power and Electrical Engineering of Riga Technical University (RTUCON), (pp. 1-6), 12-13 October 2017, Riga, Latvia.

4. Pöyry Management Consulting. (2018). Independent Aggregator Models. Final Report. Available at https://tem.fi/ documents/1410877/3481825/Itsen $\%$ C3 $\% 83 \% \mathrm{C} 2 \% \mathrm{~A} 4$ isen+aggregaattorin + mall it+26.6.2018/f63589df-49ea-4232-b39abb6973407fe2/Itsen\%C3\%83\%C2\%A4ise $\mathrm{n}+$ aggregaattorin+mallit+26.6.2018.pdf

5. de Heer, H., \& van der Laan, M. (2017). USEF: Workstream on Aggregator Implementation Models. Available at https:// www.usef.energy/app/uploads/2016/12/ Recommended-practices-for-DR-marketdesign.pdf

6. AS Augstsprieguma tīkls, Elering AS, \& Litgrid UAB. (2017). Demand Response through Aggregation - A Harmonized Approach in Baltic Region. Available at https://elering.ee/sites/default/files/public/ Elektriturg/Demand Response through Aggregation a Harmonized Approach in the Baltic....pdf.

7. Sadovica, L., Lavrinovics, V., Sauhats, A.-S., Junghans, G., \& Lehtmets, K. M. (2018). Estimating energy reduction amount in the event of demand response activation: Baseline model comparison for the Baltic States. In 2018 15th International Conference on the European Energy Market (EEM), (pp. 1-5), 27-29 June 2018, Lodz, Poland.

8. Broka, Z., \& Baltputnis, K. (2020). Handling of the rebound effect in independent aggregator framework. In 2020 17th International Conference on the European Energy Market (EEM), (pp. 1-5), 16-18 September 2020, Stockholm, Sweden.

9. Baker, P. (2017). Unleashing Demand Response with Effective Supplier Compensation. Available at http://www. raponline.org/wp-content/uploads/2017/06/ rap-baker-unleashing-demand-responseeffective-supplier-compensation-2017june.pdf.

10. SEDC. (2017). Explicit Demand Response in Europe: Mapping the Markets 2017. Smart Energy Demand Coalition, 2017. Available at http://www.smartenergydemand.eu/wpcontent/uploads/2017/04/SEDC-ExplicitDemand-Response-in-Europe-Mappingthe-Markets-2017.pdf.

11. NordREG. (2020). Nordic Regulatory Framework for Independent Aggregation. Available at http:// www.nordicenergyregulators.org/ wp-content/uploads/2020/02/A$\mathrm{New}-\mathrm{R}$ e gul a tory - F r a m ew ork for_Independent_Aggregation_NordREG_ recommendations_2020_02.pdf.

12. Competition Authority, Ministry of Economic Affairs and Communications, \& Elering AS. (2020). Proposals for the Market Framework in Estonia for Demand Response Through Independent Aggregation. Available at https://www. konkurentsiamet.ee/sites/default/files/ news-related-files/market_framework concept_for_demand_response_through independent_aggregation_ee_002.pdf.

13. Rozentale, L., Kalnbalkite, A. \& Blumberga, D. (2020). Aggregator as a new electricity market player: (Case study of Latvia). In 2020 IEEE 61st International Scientific Conference on Power and Electrical Engineering of Riga Technical University (RTUCON), 5-7 November 2020, Riga, Latvia.

14. Bray, R., \& Woodman, B. (2019). Barriers to Independent Aggregators in Europe. Available at https:/geography. exeter.ac.uk/media/universityofexeter/ schoolofgeography/images/researchgroups/ epg/Barriers_to_Independent Aggregators_in_Europe.pdf.

15. ENEFIRST. (2020). Report on International Experiences with E1st. Deliverable D2.2 of the ENEFIRST project funded by the H2020 programme. Available at https://enefirst. eu/wp-content/uploads/D2-2-Report-oninternational-experiences-with-E1st.pdf 
16. Nord Pool. (n.d.). System Price Curve Data. Available at https://www.nordpoolgroup. com/elspot-price-curves/

17. Nord Pool. (n.d.). Historical Market Data. Available at https://www.nordpoolgroup. com/historical-market-data/.

18. Nord Pool. (n.d.). How to Interpret the Information in Market Cross Point Data Reports - Nordic System Price Curves. Available at https://www.nordpoolgroup. com/4a67db/globalassets/information-inmarket-cross-point-data-reports.pdf.

19. Schwartz, D. (2017). Fast and Robust Curve Intersections. MATLAB Central File Exchange. Available at https:// se.mathworks.com/matlabcentral/ fileexchange/11837-fast-and-robust-curveintersections.

20. The Energy Market Authority. (2016). Introducing Demand Response to Enhance Competition in the National Electricity Market of Singapore. Available at https://www.ema.gov.sg/cmsmedia/ Electricity/Demand_Response/13jun16 DR Factsheet.pdf

21. Kurevska, L., Sauhats, A., Junghans, G., \& Lavrinovics, V. (2020). Measuring the impact of demand response services on electricity prices in Latvian electricity market. In 2020 IEEE 61st International Scientific Conference on Power and Electrical Engineering of Riga Technical University (RTUCON), 5-7 November 2020, Riga, Latvia.
22. Crampes, C., \& Léautier, T.-O. (2015). Subsidizing a Failed Business Model: A Premium for Residential Electricity Demand Response. FSR Energy \& Climate. Available at https://fsr.eui.eu/subsidizingfailed-busines - model-premiumresidential-electricity-demand-response/

23. Crampes, C., \& Léautier, T.-O. (2015). The Disappearing Demand Response Bonus. FSR Energy \& Climate. Available at https://fsr.eui.eu/the-disappearing-demandresponse-bonus/

24. Willems, B. \& Zhou, J. (2020). The Clean Energy Package and Demand Response: Setting Correct Incentives. Energies, 13 (21), 5672.

25. Nouicer, A., Kehoe, A.-M., Nysten, J., Fouquet, D., Hancher, L., \& Meeus, L. (2020). The EU Clean Energy Package (ed. 2020). Available at https://cadmus.eui.eu/ handle/1814/68899

26. EU. (2019). Regulation (EU) 2019/943 of the European Parliament and of the Council of 5 June 2019 on the internal market for electricity. Official Journal of the European Union. 